\title{
Drug-dominated dopamine circuits spiral addicts down to a cognitive/behavioral conflict: a neurocomputational theory
}

\author{
Mehdi Keramati*, Boris Gutkin \\ From Twenty First Annual Computational Neuroscience Meeting: CNS*2012 \\ Decatur, GA, USA. 21-26 July 2012
}

Long-term addicts find themselves powerless to resist drugs, despite knowing that drug-taking may be a harmful course of action, and an explicit motivation to quit. In controlled experiments, human addicts show a selfdescribed mistake characterized by an inconsistency between drug-seeking response and their reported subjective value. We provide a unified computational theory for this inconsistency by showing how addictive drugs gradually produce a motivational bias toward drug-seeking at low-level habitual decision processes, despite the low abstract cognitive values. This pathology emerges within the hierarchical reinforcement learning (HRL) framework when chronic drug-exposure pharmacologically hijacks the dopaminergic spirals that cascade reinforcement signal down the ventro-dorsal cortico-striatal hierarchy.

$$
\begin{gathered}
\delta_{t}^{n}=\left[r_{t}+V^{n+1}\left(s_{t+1}\right)-Q^{n}\left(s_{t}, a_{t}\right)\right]+D \\
Q^{n}\left(s_{t}, a_{t}\right) \leftarrow Q^{n}\left(s_{t}, a_{t}\right)+\alpha \cdot \delta_{t}^{n}
\end{gathered}
$$

Here, $r_{t}$ is the rewarding value of the outcome, be it natural rewards or addictive drugs. These equations show that in order to compute the prediction error

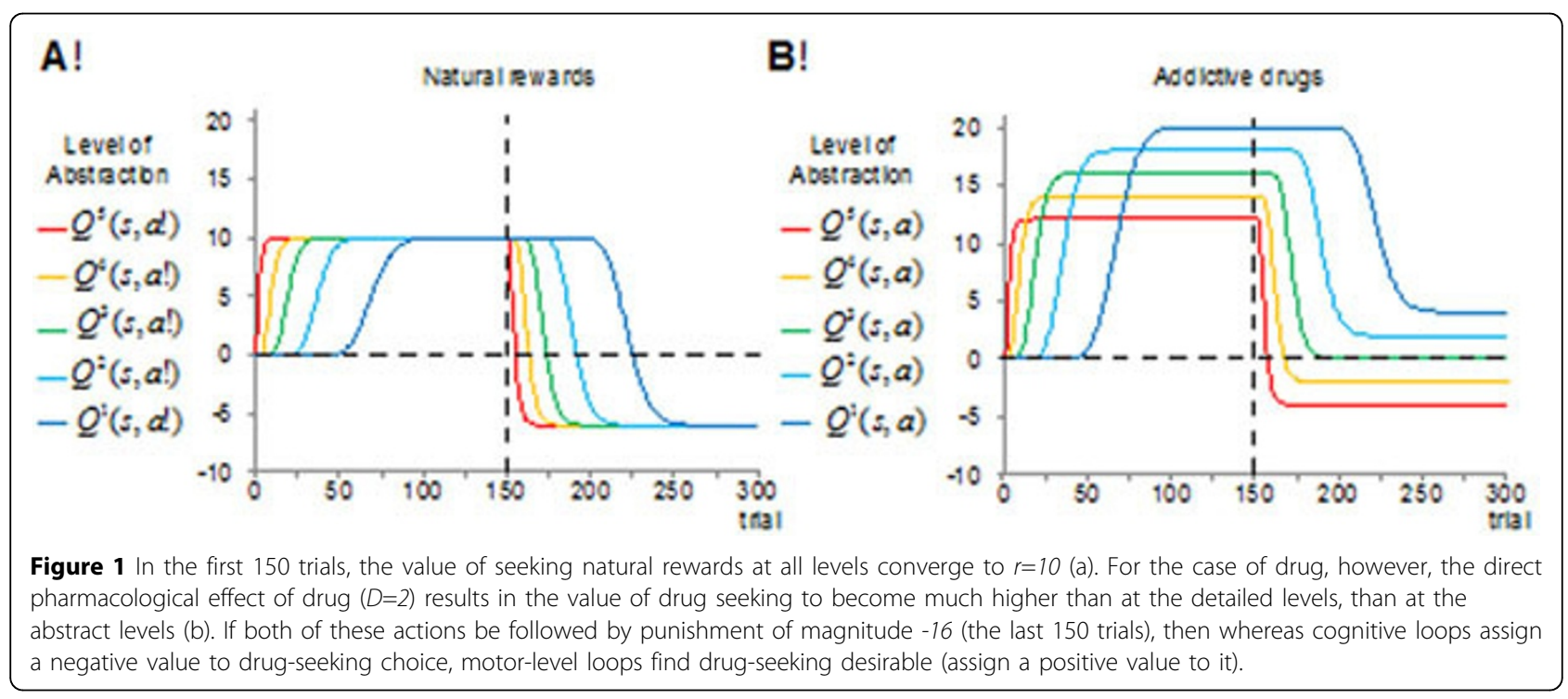

\footnotetext{
* Correspondence: mohammadmahdi.keramati@ens.fr

Group for Neural Theory, Inserm U960, Ecole Normale Superieure, Paris,
}

France 
signal for updating the value $(Q)$ of state-action pairs at the $n$-th level of decision hierarchy, the value of the temporally-advanced state $\left(s_{t+1}\right)$ comes from one higher level of abstraction $(n+1)$. This captures the role of dopamine-dependent serial connectivity linking the ventral to the dorsal striatum (known as dopamine spirals), which is suggested to integrate information across the segregated cortico-basal ganglia loops, thereby allowing more abstract levels to tune the reinforcement signal used at more detailed levels [1]. The pharmacological effect of addictive drugs on increasing the extracellular concentration of dopamine within the striatum is incorporated into this model by adding a positive term $D$ to the prediction error signal. Simulation results (Figure 1) show that drug-induced dopamine-release puts a bias on the transfer of reinforcement signal from one level of abstraction to the next. The accumulation of these biases along the rostro-caudal axis progressively induces a significant discrepancy in the value of drug-seeking behaviors at the top and bottom extremes of the hierarchy, thereby, an inconsistency between cognitive plans and motor-level habits.

Beside this central phenomenon, our model also accounts for several behavioral and neurobiological aspects of addiction, such as the gradual insensitivity of drug-seeking to drug-associated punishments (compulsivity), the delayed development of cue-elicited dopamine efflux in addicts' dorsal striatum, and the occurrence of blocking effect for drug rewards. It also suggests key testable predictions and beyond that, sets the stage for a view of addiction as a pathology of hierarchical decision making processes.

Published: 16 July 2012

\section{Reference}

1. Haruno M, Kawato M: Heterarchical reinforcement-learning model for integration of multiple cortico-striatal loops: fMRI examination in stimulus-action-reward association learning. Neural Networks 2006, 19:1242-1254

doi:10.1186/1471-2202-13-S1-08

Cite this article as: Keramati and Gutkin: Drug-dominated dopamine circuits spiral addicts down to a cognitive/behavioral conflict:

a neurocomputational theory. BMC Neuroscience 2012 13(Suppl 1):O8.
Submit your next manuscript to BioMed Central and take full advantage of:

- Convenient online submission

- Thorough peer review

- No space constraints or color figure charges

- Immediate publication on acceptance

- Inclusion in PubMed, CAS, Scopus and Google Scholar

- Research which is freely available for redistribution

Submit your manuscript at www.biomedcentral.com/submit 